\title{
Cistanche tubulosa phenylethanoid glycosides induce apoptosis in Eca-109 cells via the mitochondria-dependent pathway
}

\author{
CHANGSHUANG FU ${ }^{1}$, JINYU LI $^{2}$, ADILA AIPIRE ${ }^{1}$, LIJIE XIA $^{1}$, YI YANG ${ }^{1}$, \\ QIUYAN CHEN ${ }^{1}, \mathrm{JIE} \mathrm{LV}^{3}$, XINHUI WANG ${ }^{1}$ and JINYAO LI ${ }^{1}$ \\ ${ }^{1}$ Xinjiang Key Laboratory of Biological Resources and Genetic Engineering, College of Life Science and Technology, \\ Xinjiang University, Urumqi, Xinjiang 830046; ${ }^{2}$ College of Life Science, Xinjiang Normal University, \\ Urumqi, Xinjiang 830054; ${ }^{3}$ College of Resource and Environment Sciences, Xinjiang University, \\ Urumqi, Xinjiang 830046, P.R. China
}

Received January 25, 2018; Accepted September 19, 2018

DOI: $10.3892 /$ ol.2018.9635

\begin{abstract}
Cistanche tubulosa has various biological functions. In the present study, the antitumor effect of water-soluble phenylethanoid glycosides of C. tubulosa (CTPG-W) on esophageal cancer was investigated. Eca-109 cells were treated with CTPG-W and the cell viability was measured by MTT assay. The apoptosis, cell cycle, mitochondrial membrane potential $(\Delta \psi \mathrm{m})$ and reactive oxygen species were analyzed by flow cytometry. The levels of proteins in apoptotic pathways were detected by western blot analysis. It was determined that CTPG-W significantly reduced the viability of Eca-109 cells through the induction of apoptosis and cell cycle arrest. Following CTPG-W treatment, the $\Delta \psi \mathrm{m}$ of Eca-109 was notably decreased, which is associated with the upregulated levels of B-cell lymphoma-2 (Bcl-2)-associated $\mathrm{X}$ and downregulated levels of Bcl-2. Consequently, the levels of cytochrome $c$ and c-Jun $\mathrm{NH}_{2}$-terminal kinase were increased, which upregulated the levels of cleaved-poly (ADP-ribose) polymerase and cleaved-caspase-3, -7 and -9, but not caspase-8. Correspondingly, the levels of reactive oxygen species in Eca-109 cells demonstrated notable changes. These
\end{abstract}

Correspondence to: Professor Jinyao Li, Xinjiang Key Laboratory of Biological Resources and Genetic Engineering, College of Life Science and Technology, Xinjiang University, 666 Shengli Road, Urumqi, Xinjiang 830046, P.R. China

E-mail: ljyxju@xju.edu.cn

Dr Jinyu Li, College of Life Science, Xinjiang Normal University, 102 Xinyi Road, Urumqi, Xinjiang 830054, P.R. China

E-mail: lijinyu234@163.com

Abbreviations: CHM, Chinese herbal medicine; CTPG-W, water-soluble phenylethanoid glycosides of C. tubulosa; $\Delta \psi \mathrm{m}$, mitochondrial membrane potential; JNK, c-Jun $\mathrm{NH}_{2}$-terminal kinase; ROS, reactive oxygen species

Key words: Cistanche tubulosa, phenylethanoid glycosides, apoptosis; cell cycle, mitochondrial-dependent pathway results indicated that CTPG-W induced apoptosis of Eca-109 cells through a mitochondrial-dependent pathway.

\section{Introduction}

Esophageal cancer is one of the most common cancer types with the 11th highest morbidity rate and 6th highest mortality rate globally, and caused $\sim 439,000$ mortalities in 2015 (1). The incidence of esophageal cancer notably varies among different regions, with eastern Asia and eastern and southern Africa exhibiting the highest rates of incidence and western Africa exhibiting the lowest rates in 2012 (1,2). In China, the estimated esophageal cancer cases and mortalities were 477,000 and 375,000, respectively, in 2015 (3). Although the morbidity rate of esophageal cancer has decreased in middle and high-middle sociodemographic index countries between 2005 and 2015, the mortality rate remains high due to the poor prognosis $(1,4)$. The combination of surgical resection with chemotherapy or radiotherapy has been used to treat esophageal cancer, however, it has been reported that between 2003 and 2014 the 5-year survival rate remained $<20 \%$ in China, USA and Europe $(4,5)$. For these reasons, it is urgent to develop novel therapeutic agents to treat esophageal cancer.

Traditional Chinese herbal medicine (CHM) has been used to treat various cancer types, including non-small cell lung cancer (6), colorectal cancer (7), hepatocellular carcinoma (8). Recently, the clinical trials reported that the combination of CHM with chemotherapy or radiotherapy not only demonstrated a number of benefits on the quality of life and alleviating side effects induced by chemotherapy or radiotherapy $(9,10)$, but also improved the survival rate of patients with non-small cell lung, liver, gastric, colorectal, nasopharyngeal or cervical cancer (9). However, there is conflicting evidence regarding the efficacy of CHM treatment on esophageal cancer $(10,11)$. Numerous studies determined that a number of herbal medicines or components could inhibit the growth of esophageal cancer cells in vitro and in vivo, including Andrographis paniculata $(12,13)$, Daikenchuto (14), icariin (15), Rosa Roxburghii Tratt and Fagopyrum Cymosum (16), Jaridonin (17), Marsdenia tenacissima (18), OP16 (a novel ent-kaurene diterpenoid) (19), 
Qigesan (20) and Tonglian decoction (21). Cistanche is a type of CHM and exerts various biological functions, including anti-oxidation, anti-inflammation and neuroprotection $(22,23)$. Our previous study demonstrated that Cistanche tubulosa phenylethanoid glycosides (CTPG) could suppress the growth of melanoma B16-F10 cells in vitro and in vivo (24). However, the poor water solubility of CTPG previously used limits the drug development (24). Therefore, water-soluble CTPG (CTPG-W) was used and the antitumor effect on esophageal cancer cells (Eca-109) was investigated. It was determined that CTPG-W could dose-dependently inhibit the viability of Eca-109 cells through the induction of apoptosis via a mitochondrial-dependent pathway.

\section{Materials and methods}

Animals. Female C57BL/6 mice (6-8 weeks, $\sim 25 \mathrm{~g}$ ) were purchased from the Beijing Laboratory Animal Research Center (Beijing, China) and housed in the temperature-controlled $\left(25^{\circ} \mathrm{C}\right)$, light-cycled (12/12) Animal Facility of Xinjiang University (Urumqi, China). All animals received pathogen-free water and food.

Cell line and culture. The human esophageal carcinoma cell line (Eca-109) was preserved by the Xinjiang Key Laboratory of Biological Resources and Genetic Engineering (College of Life Science and Technology, Xinjiang University, Urumqi, China) and cultured in RPMI-1640 medium (Gibco; Thermo Fisher Scientific, Inc., Waltham, MA, USA) supplemented with $10 \%$ heat-inactivated fetal bovine serum (FBS; MRC, EN MOASAI Biological Technology Co., Ltd, Jiangsu, China), $1 \%$ L-glutamine $(100 \mathrm{mM}), 100 \mathrm{U} / \mathrm{ml}$ penicillin and $100 \mu \mathrm{g} / \mathrm{ml}$ streptomycin at $37^{\circ} \mathrm{C}$ in a humidified atmosphere containing $5 \% \mathrm{CO}_{2}$.

High performance liquid chromatography (HPLC). CTPG-W (cat. no. SGJG20170410) was purchased from Shanghai Upbio Tech Co., Ltd. (Shanghai, China). The major compounds of CTPG were qualified and quantified by HPLC according to our previous study (24). Briefly, HPLC was conducted on a ZORBAX SB-C18 Column (250x4.6 mm; $5 \mu \mathrm{m})$ at $30^{\circ} \mathrm{C}$ and eluted with $0.2 \%$ formic acid solution and a gradient of methanol starting at $23 \%$, as $1 \mathrm{ml}$ was added every min for $45 \mathrm{~min}$ until reaching $31 \%$. A total of $10 \mu \mathrm{l}$ sample was injected and detected at $330 \mathrm{~nm}$. The echinacoside standard was purchased from Shanghai Baoban Biotech Co., Ltd. (Shanghai, China), and acteoside standard was purchased from Sigma-Aldrich (Merck KGaA, Darmstadt, Germany). The standards were used to analyze the components of CTPG-W.

MTT assay. Cell proliferation was measured with an MTT assay. Eca-109 cells were inoculated into 96-well plates at a density of $5 \times 10^{3}$ cells in $100 \mu \mathrm{l}$ RPMI-1640 medium/well and cultured at $37^{\circ} \mathrm{C}$ for $24 \mathrm{~h}$, then treated by different concentrations $(0,200,400,600$ and $800 \mu \mathrm{g} / \mathrm{ml})$ of CTPG-W or $0.4 \%$ dimethyl sulfoxide (DMSO) for 24, 48 and $72 \mathrm{~h}$. DMSO was used as solvent control $(800 \mu \mathrm{g} / \mathrm{ml}$ CTPG-W containing $0.4 \%$ DMSO). Cisplatin $(20 \mu \mathrm{g} / \mathrm{ml})$ was used as the positive control. Subsequently, the supernatant was discarded following centrifugation at $225 \mathrm{x}$ g for $5 \mathrm{~min}$ at room temperature and
$100 \mu 1$ MTT solution $(0.5 \mathrm{mg} / \mathrm{ml}$ in RPMI-1640 medium without FBS) was added to each well and incubated at $37^{\circ} \mathrm{C}$ for $3 \mathrm{~h}$. The formed formazan crystals were dissolved in $200 \mu \mathrm{l}$ DMSO. The optical density (OD) values were measured at a wavelength of $490 \mathrm{~nm}$ by a 96 -well microplate reader (Bio-Rad Laboratories, Inc., Hercules, CA, USA). The relative cell viability was calculated according to the formula: Cell viability $(\%)=\left(\mathrm{OD}_{\text {treated }} / \mathrm{OD}_{\text {untreated }}\right) \times 100 \%$. The morphology of Eca-109 cells was observed with an inverted fluorescence microscope (magnification, x200) (Nikon Eclipse Ti-E; Nikon Corporation, Tokyo, Japan).

For the proliferation of splenocytes, C57BL/6 mice were euthanized by cervical dislocation and spleens were isolated. The single cell suspension was made and splenocytes were seeded into 96 -well plates at a density of $1 \times 10^{5}$ cells/well in $100 \mu 1$ RPMI-1640 medium, and then treated with different concentrations $(0,200,400,600$ and $800 \mu \mathrm{g} / \mathrm{ml})$ of CTPG-W for 24,48 and $72 \mathrm{~h}$ at $37^{\circ} \mathrm{C}$ with $5 \% \mathrm{CO}_{2}$. The proliferation of splenocytes was measured by MTT assay, according to the aforementioned protocol. Stimulatory index $=\mathrm{OD}_{\text {treated }} / \mathrm{OD}_{\text {untreated }}$.

Measurement of apoptosis and the cell cycle. Eca-109 cells were cultured in $60 \mathrm{~mm}$ dishes at a density of $2.5 \times 10^{5}$ cells/dish for $24 \mathrm{~h}$ and treated with different concentrations $(0,200,400$, 600 and $800 \mu \mathrm{g} / \mathrm{ml}$ ) of CTPG-W or $0.4 \%$ DMSO for $24 \mathrm{~h}$ at $37^{\circ} \mathrm{C}$ with $5 \% \mathrm{CO}_{2}$. Cells were collected and stained with an Annexin V-fluorescein isothiocyanate (FITC)/Propidium iodide (PI) Apoptosis Detection kit (Shanghai Shengsheng Biotechnology Co., Ltd., Shanghai, China), according to the manufacturer's protocols. Samples were collected by flow cytometry (BD FACSCalibur; BD Biosciences, Franklin Lakes, NJ, USA) and analyzed by FlowJo 7.6 (Tree Star, Inc., Ashland, OR, USA). To analyze the effect of CTPG-W on the cell cycle, $2.5 \times 10^{5}$ Eca-109 cells were seeded in $60 \mathrm{~mm}$ culture dishes and treated with CTPG-W $(0,100,200$ and $400 \mu \mathrm{g} / \mathrm{ml}$ ) or $0.4 \%$ DMSO for $24 \mathrm{~h}$ at $37^{\circ} \mathrm{C}$ with $5 \% \mathrm{CO}_{2}$. All cells were harvested and washed twice with ice-cold PBS (Gibco; Thermo Fisher Scientific, Inc.), then fixed in $70 \%$ ice-cold ethanol at $4^{\circ} \mathrm{C}$ for $30 \mathrm{~min}$. Following washing twice with ice-cold PBS, cells were resuspended in $300 \mu \mathrm{l} \mathrm{PI} / \mathrm{RNase}$ staining buffer (BD Biosciences, San Jose, CA, USA) for $10 \mathrm{~min}$ at room temperature. The cell cycle distribution was analyzed with the ModFit LT 3.0 software by flow cytometry (BD FACSCalibur).

Analysis of mitochondrial membrane potential $(\Delta \psi m)$ and reactive oxygen species (ROS). To analyze the $\Delta \psi \mathrm{m}$, Eca-109 cells were treated with CTPG-W $(0,400,600$ and $800 \mu \mathrm{g} / \mathrm{ml})$ or $0.4 \%$ DMSO for $24 \mathrm{~h}$ at $37^{\circ} \mathrm{C}$ with $5 \% \mathrm{CO}_{2}$, and stained with the Mitochondrial membrane potential assay kit with JC-1 (Beyotime Institute of Biotechnology, Shanghai, China), according to the manufacturer's protocol, for $20 \mathrm{~min}$ at $37^{\circ} \mathrm{C}$. Following washing twice with JC-1 washing buffer (Beyotime Institute of Biotechnology), samples were resuspended with $300 \mu \mathrm{l}$ JC-1 washing buffer and analyzed by flow cytometry (BD FACSCalibur). The fluorescence of JC-1 dye in Eca-109 cells was also observed with an inverted fluorescence microscope (magnification, x200; Nikon Eclipse Ti-E). For analysis of ROS, Eca-109 cells were treated with CTPG-W $(0,400,600$ and $800 \mu \mathrm{g} / \mathrm{ml})$ for $2,4,6,12$ and $24 \mathrm{~h}$, and 

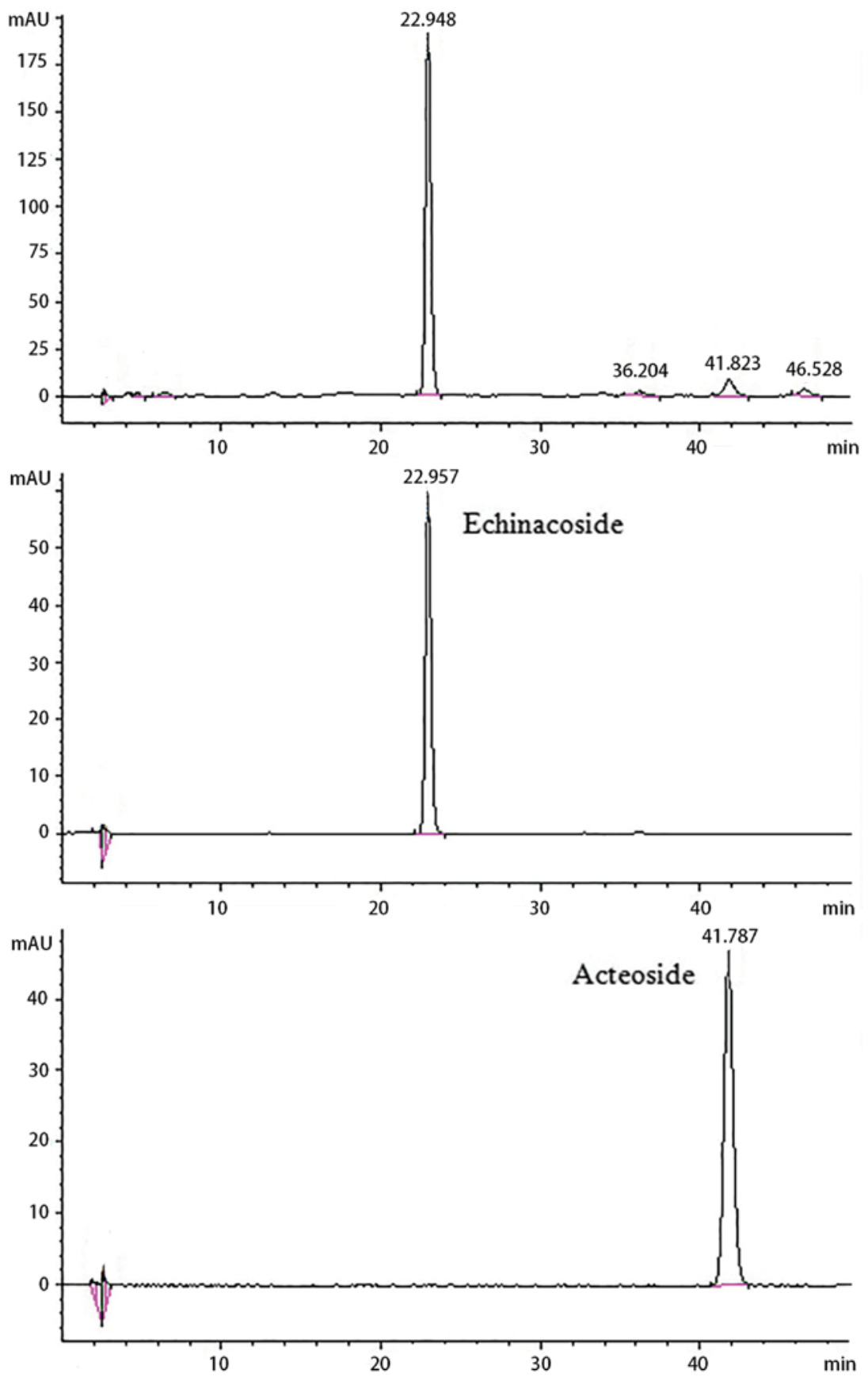

Figure 1. The qualify control of CTPG-W. The components of CTPG-W were qualitatively and quantitatively analyzed by high performance liquid chromatography and compared with the standards of echinacoside and acteoside. CTPG-W, water-soluble phenylethanoid glycosides of C. tubulosa.

stained with Reactive Oxygen Species Assay kit (Beyotime Institute of Biotechnology), according to the manufacturer's protocol, for $20 \mathrm{~min}$ at $37^{\circ} \mathrm{C}$. Following washing three times with ice-cold PBS, samples were collected by flow cytometry (BD FACSCalibur) and analyzed by FlowJo 7.6 software.

2,2-diphenyl-1-picrylhydrazyl (DPPH) radical scavenging activity. The free radical scavenging activity of CTPG-W was determined with a DPPH free radical assay according to the published protocol with a minor modification, as methanol was substituted with ethanol to dissolve DPPH $(25,26)$. For steady state measurements, $150 \mu 1 \mathrm{DPPH}(100 \mathrm{mmol} / \mathrm{l})$ in ethanol was mixed with different concentrations of CTPG-W $(25,50,75$,
$100,250,300,400,500$ and $600 \mu \mathrm{g} / \mathrm{ml})$ in $50 \mu \mathrm{l} \mathrm{PBS}$, and incubated in the dark for $30 \mathrm{~min}$ at room temperature. The absorbance at $517 \mathrm{~nm}$ was detected in the presence and absence of CTPG-W. A total of $50 \mu \mathrm{l}$ Vitamin C was used as the positive control. The DPPH radical scavenging activity was calculated using the formula: Scavenging $(\%)=\left[1-\left(\mathrm{A}_{\text {sample }}-\mathrm{A}_{\text {blank }}\right) / \mathrm{A}_{0}\right] \times 100$, where $A_{\text {blank }}$ is the absorbance of the control (without DPPH), $\mathrm{A}_{\text {sample }}$ is the absorbance of the sample and $\mathrm{A}_{0}$ is the absorbance of PBS with DPPH.

Western blot analysis. Eca-109 cells were treated with CTPG-W $(0,200,600 \mu \mathrm{g} / \mathrm{ml})$ or $0.4 \%$ DMSO for $24 \mathrm{~h}$ at $37^{\circ} \mathrm{C}$ with $5 \% \mathrm{CO}_{2}$. Following washing twice with PBS, cells 
A

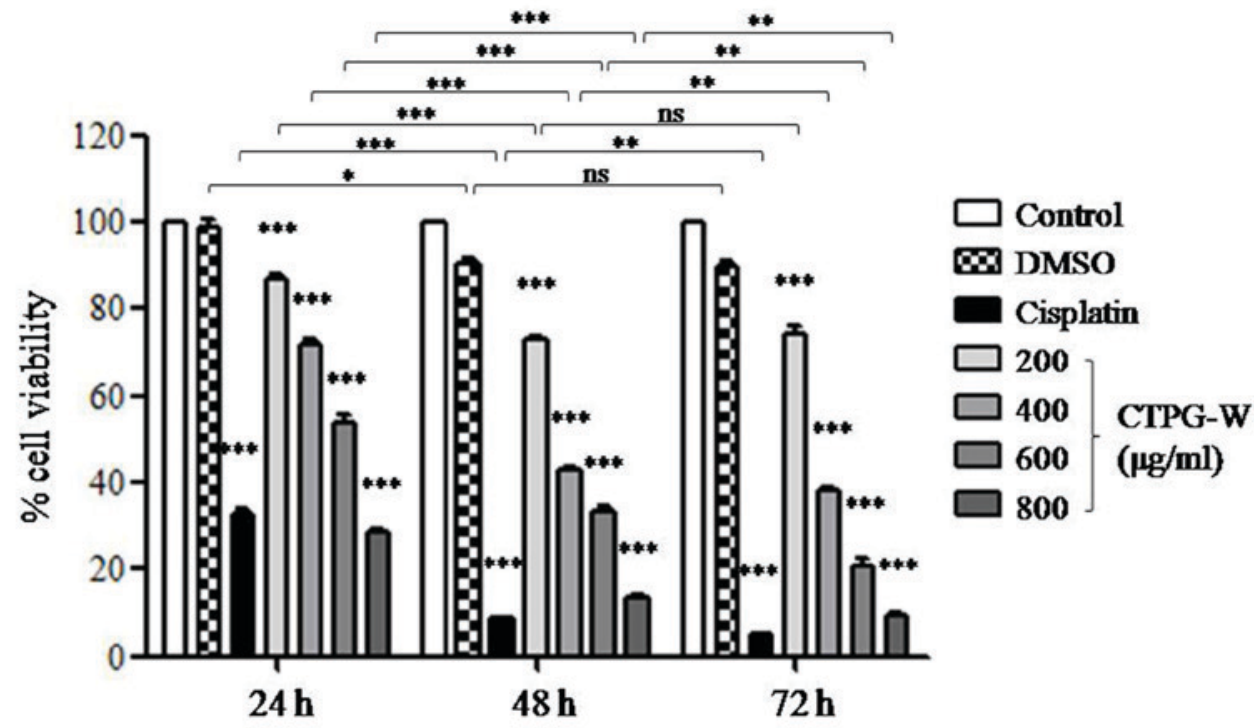

B

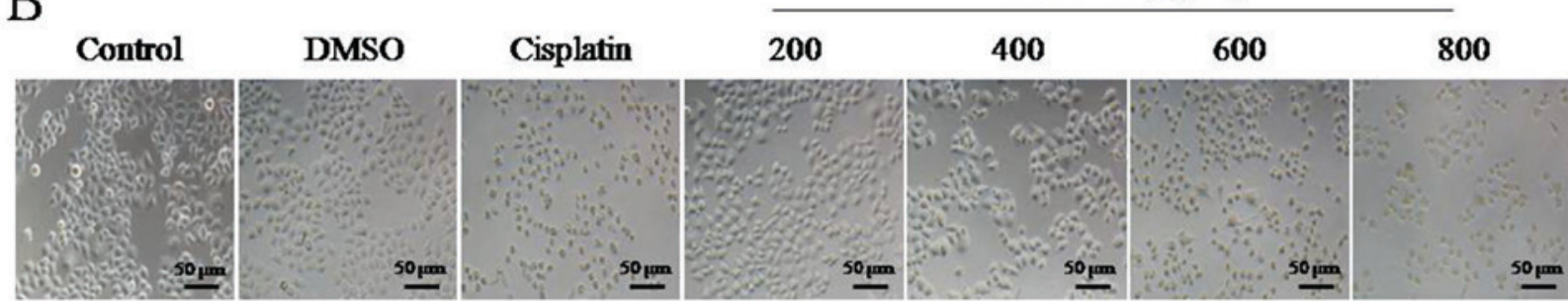

$\mathrm{C}$

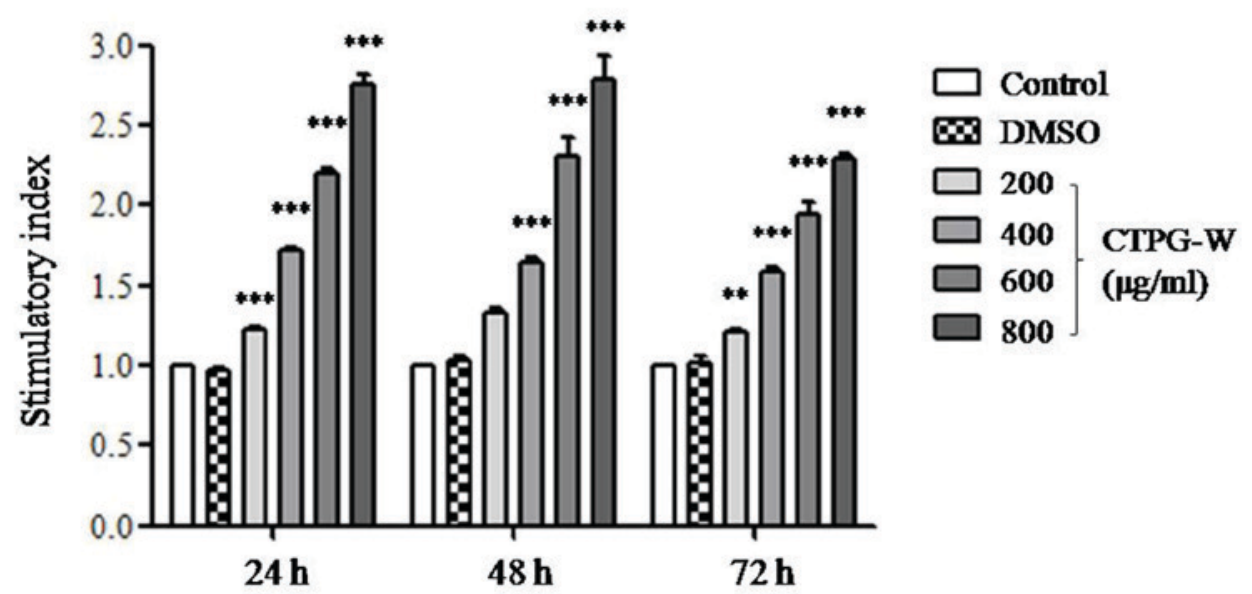

Figure 2. The effect of CTPG-W on the growth of Eca-109 cells and splenocytes. (A) Eca-109 cells were treated by different concentrations of CTPG-W for 24, 48 and $72 \mathrm{~h}$, and then cell viability was detected with an MTT assay. (B) The morphological changes of Eca-109 cells upon CTPG-W treatment at 24 h. (C) Splenocytes of C57BL/6 mice were treated with different concentrations of CTPG-W for 24, 48 and $72 \mathrm{~h}$, and then the proliferation was analyzed with an MTT assay. ${ }^{* *} \mathrm{P}<0.01$ and ${ }^{* * *} \mathrm{P}<0.001$, compared with the control. CTPG-W, water-soluble phenylethanoid glycosides of $C$. tubulosa.

were lysed in Radioimmunoprecipitation Assay Lysis buffer (Beijing ComWin Biotech Co., Ltd., Beijing, China) for $20 \mathrm{~min}$ on ice. After centrifugation at $10,000 \times \mathrm{g}$ for $10 \mathrm{~min}$ at $4^{\circ} \mathrm{C}$, the supernatants were collected, and protein concentrations were detected with a bicinchoninic acid kit (Thermo Fisher Scientific, Inc.) according to the manufacturer's protocols. Western blot analysis was conducted according to our previous description (24). The antibodies against caspase-7 (cat. no. D120077), caspase-8 (cat. no. D155240), caspase-9 (cat. no. D220078), B-cell lymphoma-2 (Bcl-2)-associated X (Bax) (cat.no. D220073) and Bcl-2 (cat.no. D260117), and anti-mouse IgG-horseradish peroxidase (HRP) (cat. no. D111050) and anti-rabbit IgG-HRP (cat. no. D110058) were purchased from BBI Life Sciences (Shanghai, China). The antibodies against caspase-3 (cat. no. E-AB-10050) and active caspase-3 (cat. no. E-AB-22115) were bought from Elabscience (Wuhan, China). Other antibodies against caspase-7 (cat. no. 9492), poly (ADP-ribose) polymerase (PARP) (cat. no. 9542), cytochrome $c$ (cat. no. AC909), c-Jun $\mathrm{NH}_{2}$-terminal kinase (JNK) (cat. no. 9252S) and $\beta$-actin (cat. no. 58169) were obtained from Cell Signaling Technology, Inc. (Danvers, MA, USA). All primary and secondary antibodies were diluted at 1:1,000. The primary antibodies were incubated at $4^{\circ} \mathrm{C}$ overnight and the secondary antibodies were incubated at $37^{\circ} \mathrm{C}$ for $1 \mathrm{~h}$. 
A

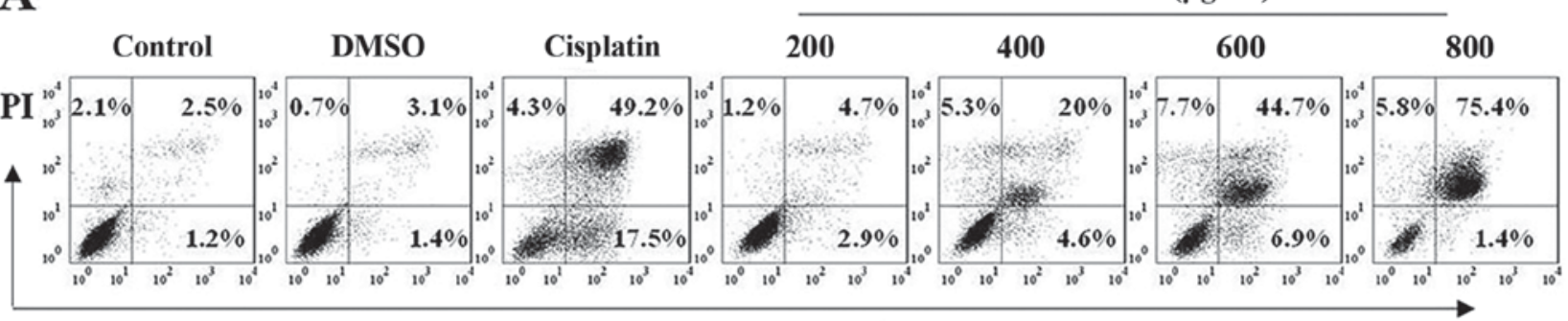

Annexin V
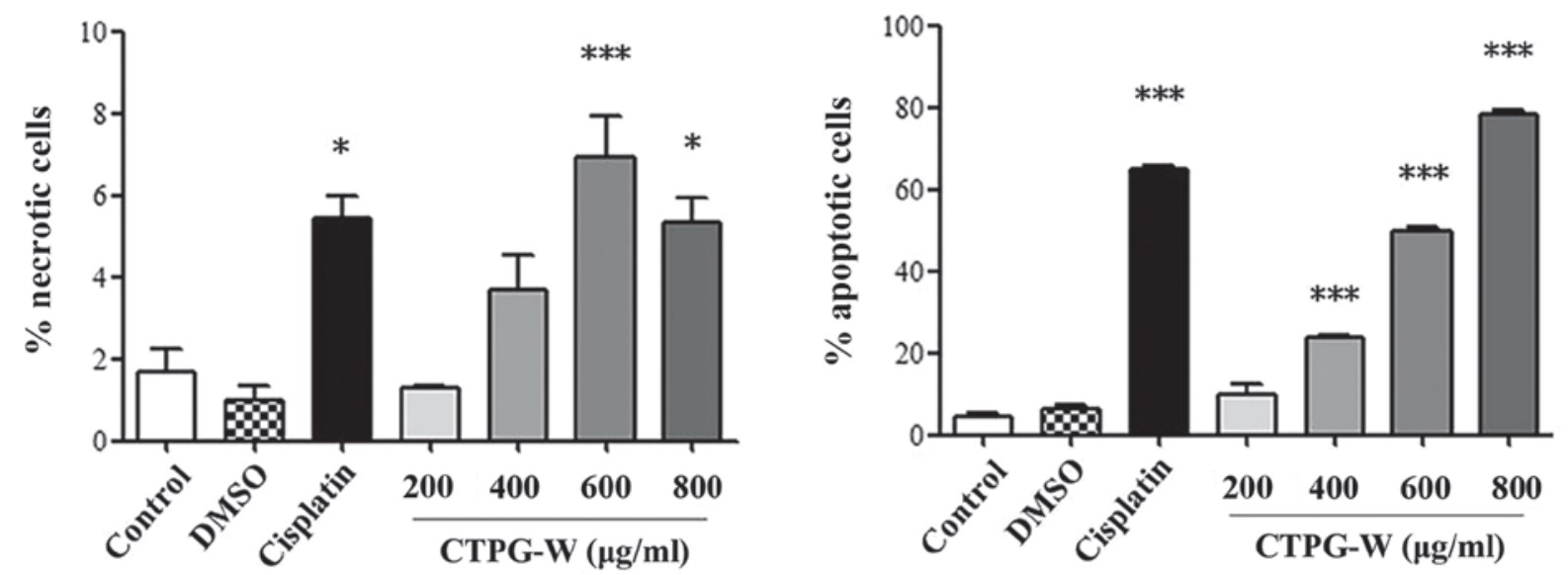

B

CTPG-W $(\mu \mathrm{g} / \mathrm{ml})$

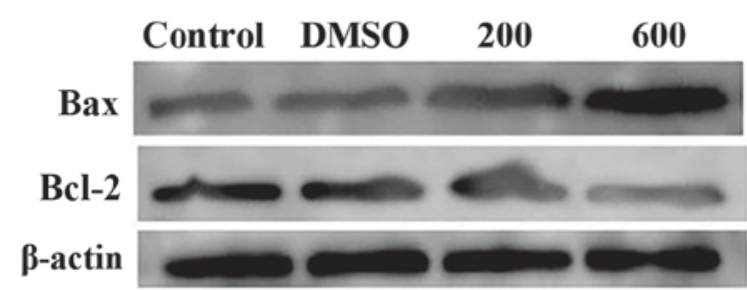

Figure 3. The apoptosis of Eca-109 cells induced by CTPG-W. Cells were treated with different concentrations of CTPG-W for $24 \mathrm{~h}$. (A) The apoptotic and necrotic Eca-109 cells were analyzed by flow cytometry. The upper panel depicts the individual dot plots and the lower panel depicts the summary data. ${ }^{*} \mathrm{P}<0.05$ and $^{* * * *} \mathrm{P}<0.001$, compared with the control. (B) Total protein was isolated and the expression levels of Bax and Bcl-2 were detected with western blot analysis. Bcl-2, B-cell lymphoma-2; Bax, Bcl-2-associated X; DMSO, dimethyl sulfoxide; CTPG-W, water-soluble phenylethanoid glycosides of $C$. tubulosa .

The target proteins were detected using enhanced chemiluminescence assay kit (Beyotime Institute of Biotechnology), according to the manufacturer's protocol.

Statistical analysis. Statistical significance was calculated by one-way analysis of variance with Tukey's post hoc test and results were analyzed using GraphPad Prism 5.0 software (GraphPad Software, La Jolla, CA, USA) among the treatment and control groups. All data were presented as the mean \pm standard deviation. $\mathrm{P}<0.05$ was considered to indicate a statistically significant difference.

\section{Results}

$C T P G$-W suppresses the growth of Eca-109 cells. The components of CTPG-W were qualified and quantified by HPLC (Fig. 1), which were compared with the standards of echinacoside and acteoside. According to the peak retention times and the peak areas, CTPG-W contained $39.16 \%$ of echinacoside and $2.44 \%$ of acteoside. Firstly, the effect of CTPG-W on the viability of Eca-109 cells was determined with an MTT assay. CTPG-W was dissolved in DMSO at $200 \mathrm{mg} / \mathrm{ml}$ and diluted with RPMI-1640 medium containing 10\% heat-inactivated FBS to indicated concentrations. Eca-109 cells were treated with CTPG-W and cell viability was analyzed with an MTT assay at the indicated time points. CTPG-W treatment significantly reduced the viability of Eca-109 cells in a dose- and time-dependent manner $(\mathrm{P}<0.001$; Fig. 2A). The morphology of Eca-109 cells was observed with an inverted fluorescence microscope (magnification, x200) following CTPG-W treatment for $24 \mathrm{~h}$, which changed notably in a dose-dependent manner, with the cells shrinking and becoming round following CTPG-W treatment (Fig. 2B). These results indicate that CTPG-W suppresses the growth of Eca-109 cells. The effect of CTPG-W on the proliferation of splenocytes was also detected with an MTT assay. CTPG-W significantly promoted the proliferation of splenocytes in a dose-dependent manner (Fig. 2C), indicating that it has no cytotoxic effect on splenocytes. 

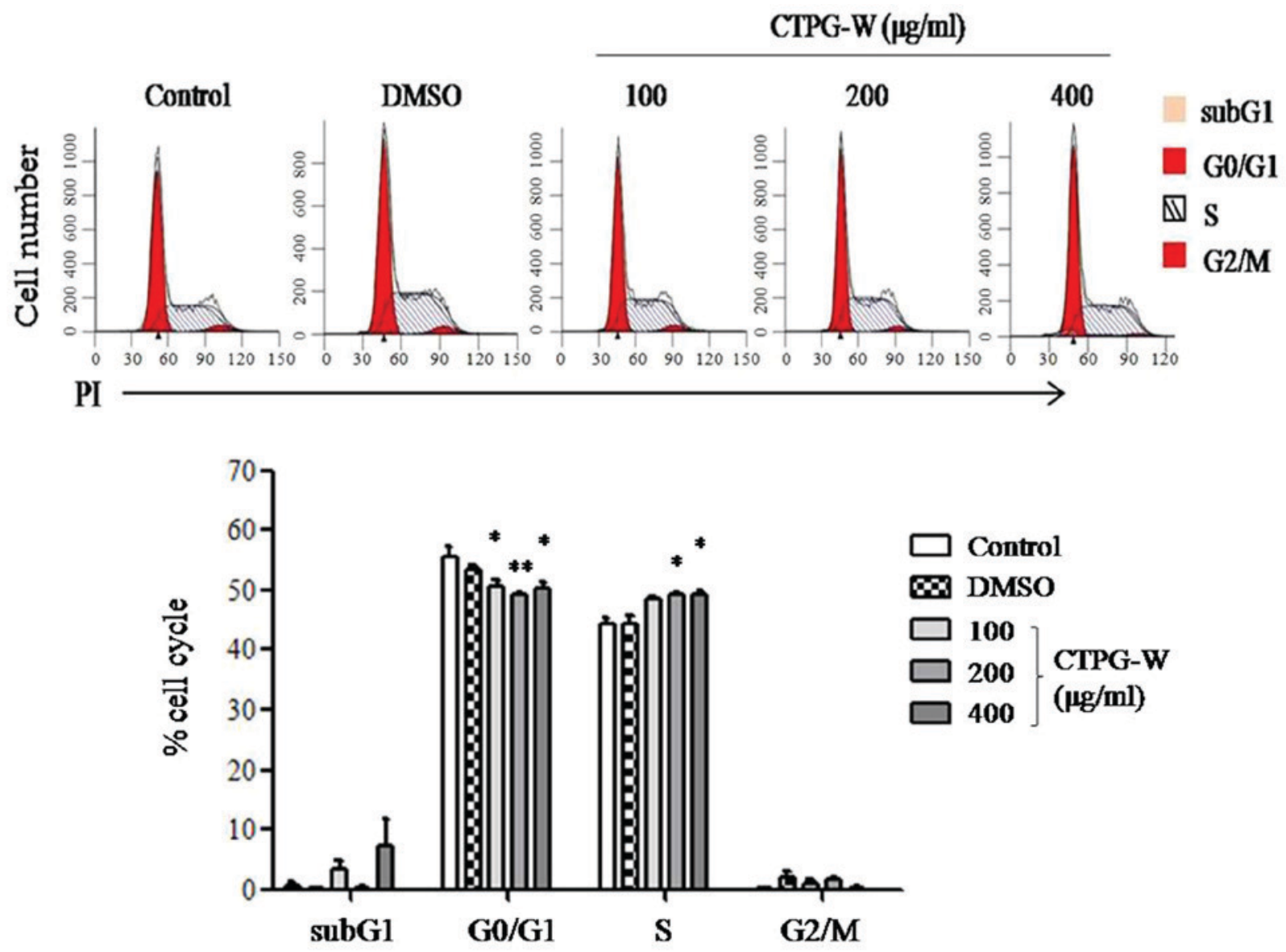

Figure 4. The effect of CTPG-W on cell cycle distribution in Eca-109 cells. Different concentrations of CTPG-W were used to treat Eca-109 cells for $24 \mathrm{~h}$ and cell cycle distribution was analyzed by flow cytometry. ${ }^{*} \mathrm{P}<0.05$ and ${ }^{* *} \mathrm{P}<0.01$, compared with the control. DMSO, dimethyl sulfoxide; CTPG-W, water-soluble phenylethanoid glycosides of C. tubulosa.

CTPG-W induces apoptosis in Eca-109 cells. To investigate whether CTPG-W suppressed the growth of Eca-109 cells through the induction of apoptosis or necrosis, cells were treated with different concentrations of CTPG-W. After $24 \mathrm{~h}$, the apoptosis and necrosis of Eca-109 cells were detected with Annexin V/PI staining. As depicted in Fig. 3A, Annexin $\mathrm{V}^{-} / \mathrm{PI}^{+}$cells were gated as necrotic cells, and Annexin $\mathrm{V}^{+} / \mathrm{PI}^{+}$and Annexin $\mathrm{V}^{+} / \mathrm{PI}^{-}$cells were gated as apoptotic cells. CTPG-W primarily induced the apoptosis of Eca-109 cells in a dose-dependent manner, although the necrotic Eca-109 cells also increased significantly under the treatment of 600 and $800 \mu \mathrm{g} / \mathrm{ml} \mathrm{CTPG-W}(\mathrm{P}<0.001$ at $600 \mu \mathrm{g} / \mathrm{ml}$ and $\mathrm{P}<0.05$ at $800 \mu \mathrm{g} / \mathrm{ml}$ ). Consistently, the levels of pro-apoptotic Bax and anti-apoptotic Bcl-2 in Eca-109 cells were upregulated and downregulated, respectively, upon CTPG-W treatment (Fig. 3B). The results indicated that CTPG-W primarily inhibited the growth of Eca-109 cells through the induction of apoptosis.

CTPG-W induces cell cycle arrest at the S phase in Eca-109 cells. Disturbance of the cancer cell cycle will suppress cell growth and promote apoptosis (27). The distribution of the cell cycle in Eca-109 cells was detected with PI staining following CTPG-W treatment for $24 \mathrm{~h}$. It was observed that cells in the $S$ phase increased and cells in the $G_{0} / G_{1}$ phases indicated an overall significant decrease upon CTPG-W treatment $(\mathrm{P}<0.05$;
Fig. 4), indicating that CTPG-W arrests the Eca-109 cell cycle at the $\mathrm{S}$ phase.

$C T P G-W$ decreases $\Delta \psi m$ and induces the release of cytochrome $c$. Apoptosis can be induced by a mitochondrial-dependent pathway $(28,29)$. The pro- and anti-apoptotic members of the BCL-2 protein family serve important roles in the regulation of mitochondrial membrane integrity $(30,31)$. Following CTPG-W treatment for $24 \mathrm{~h}$, the $\Delta \psi \mathrm{m}$ was assessed using JC-1 staining. JC-1 aggregate (red fluorescence detected in FL-2) will disintegrate into monomer (green fluorescence detected in FL-1) when $\Delta \psi \mathrm{m}$ is reducing (32). As depicted in Fig. 5A, the frequencies of $\mathrm{FL}-1^{+} \mathrm{FL}-2^{-/+}$cells increased significantly in a dose-dependent manner, indicating that the $\Delta \psi \mathrm{m}$ of Eca-109 cells decreased. The fluorescence changes in Eca-109 cells were also observed with an inverted fluorescence microscope (Fig. 5B). With the increasing concentrations of CTPG-W, the red fluorescence decreased and the green fluorescence increased, which is consistent with the data from flow cytometry. It was also observed that the level of cytochrome $c$ in cytosol was notably increased (Fig. 5C), which is a result of a reduction of $\Delta \psi \mathrm{m}$. This reinforces the conclusion drawn from the increased count of $\mathrm{FL}-1^{+} \mathrm{FL}-2^{-/+}$cells that $\Delta \psi \mathrm{m}$ decreased as a result of CTPG-W treatment. It has reported that JNK can regulate the activation of the BCL-2 protein family causing the release of cytochrome $c$ (33-35). It was 
A

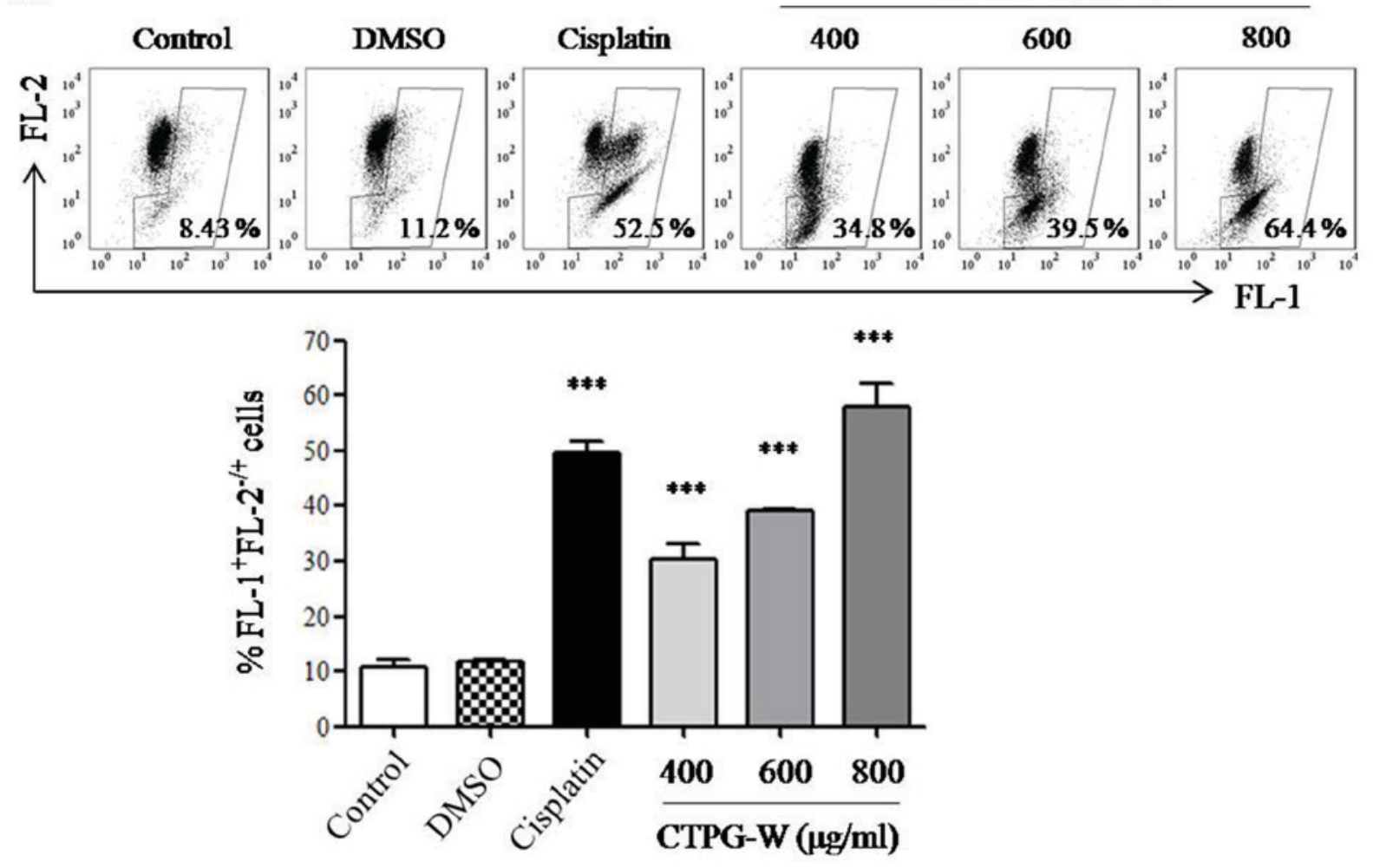

$\mathrm{B}$
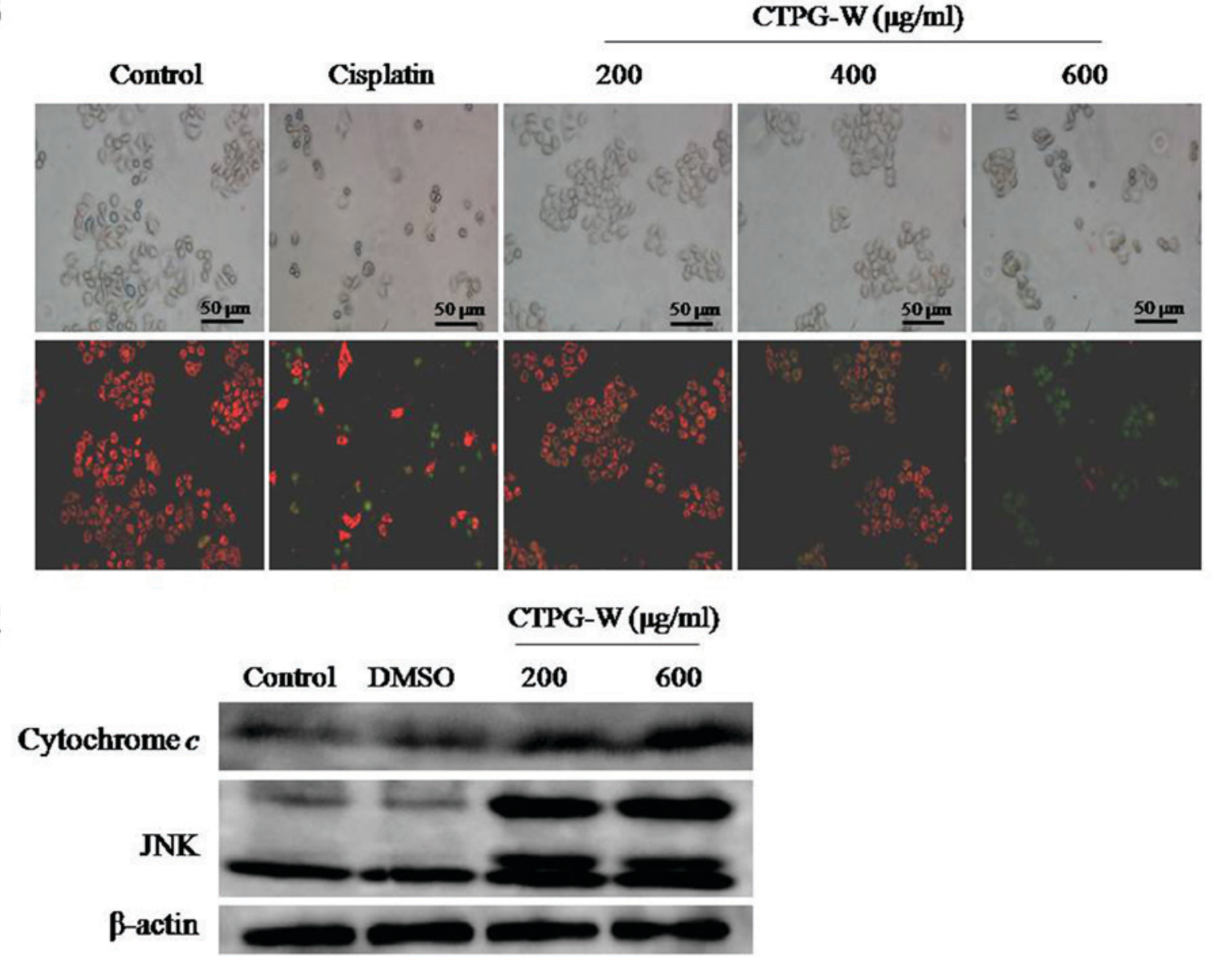

Figure 5. The reduction of $\Delta \psi \mathrm{m}$ and upregulation of cytochrome $c$ and JNK. Eca-109 cells were treated with different concentrations of CTPG-W for $24 \mathrm{~h}$. (A) $\Delta \psi \mathrm{m}$ was detected by JC-1 staining and samples were analyzed by flow cytometry. The individual dot plots depict the changes of JC-1 fluorescence. The frequencies of FL- $1^{+} \mathrm{FL}-2^{-1+}$ cells are depicted in the lower panel. ${ }^{* * *} \mathrm{P}<0.001$, compared with the control. (B) The changes of JC-1 fluorescence were observed with an inverted fluorescence microscope. (C) The levels of cytochrome $c$ and JNK were detected with western blot analysis. The different bands of JNK represent 54 and $46 \mathrm{kDa}$ proteins. DMSO, dimethyl sulfoxide; CTPG-W, water-soluble phenylethanoid glycosides of $C$. tubulosa; JNK, c-Jun $\mathrm{NH}_{2}$-terminal kinase. 


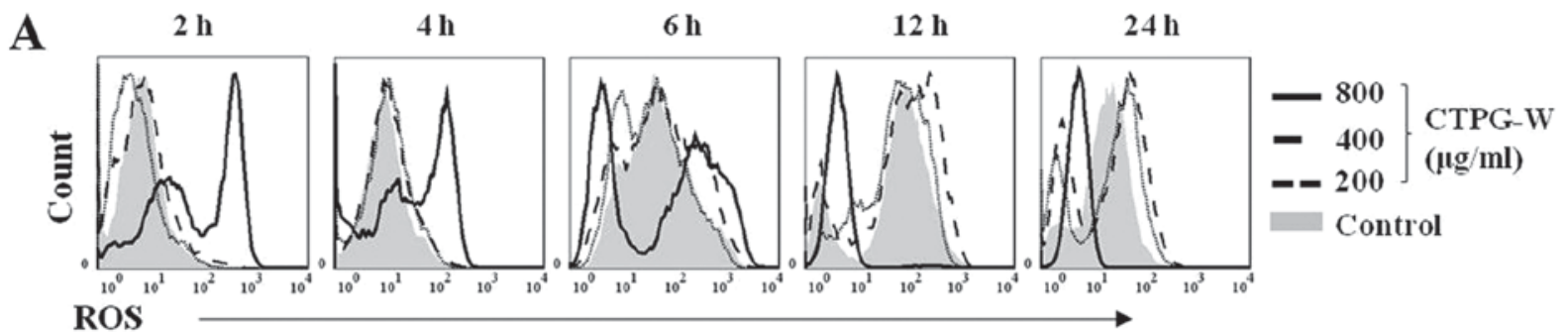

ROS
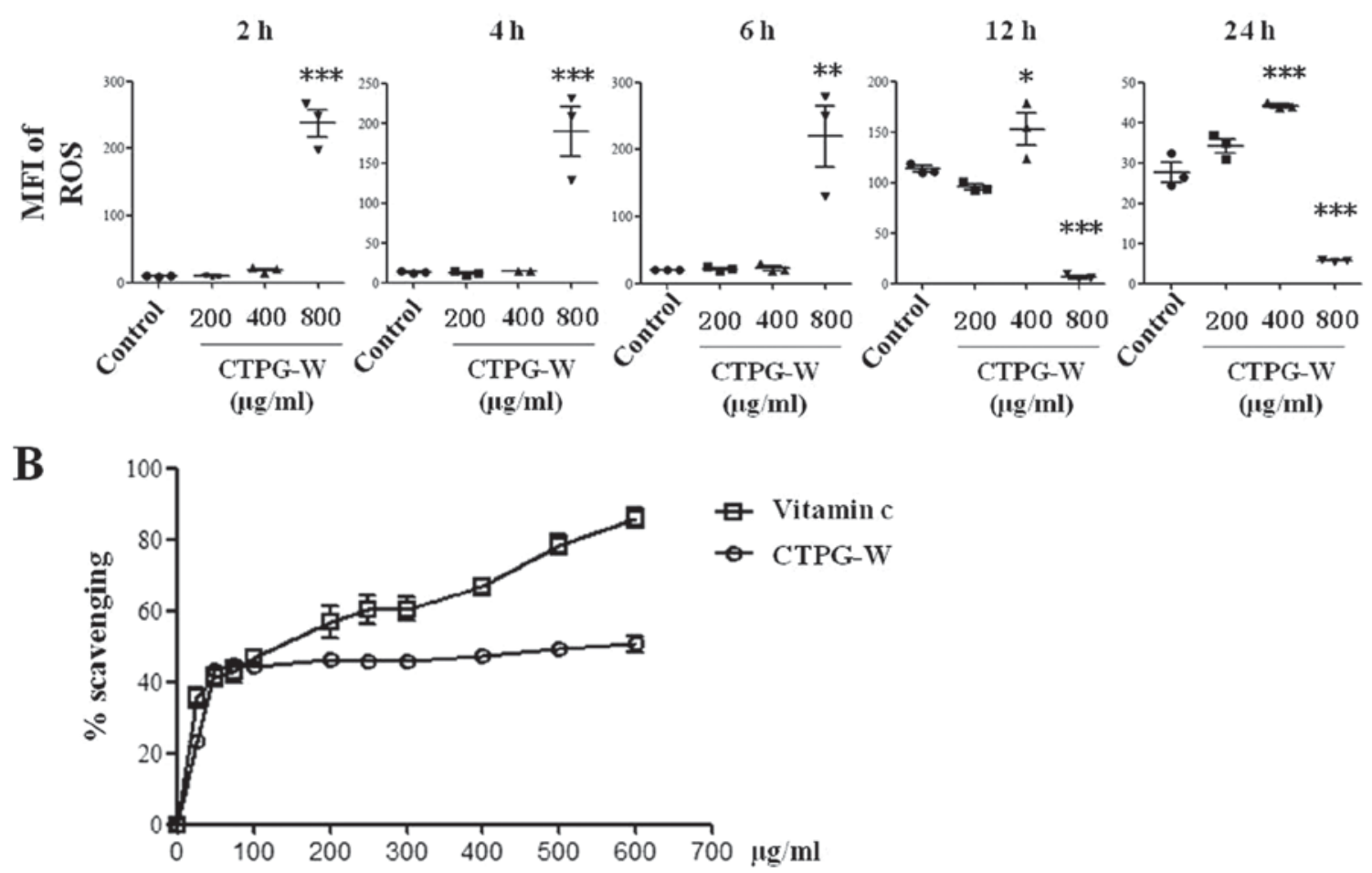

Figure 6. The levels of ROS in Eca-109 cells upon CTPG-W treatment and the antioxidant activity of CTPG-W. (A) Eca-109 cells were treated with different concentrations of CTPG-W and the levels of ROS were analyzed by flow cytometry at indicated time points. ${ }^{*} \mathrm{P}<0.05,{ }^{* * *} \mathrm{P}<0.01$ and ${ }^{* * * *} \mathrm{P}<0.001$, compared with the control. (B) The free radical scavenging activity of CTPG-W was determined with a 2,2-diphenyl-1-picrylhydrazyl assay. CTPG-W, water-soluble phenylethanoid glycosides of C. tubulosa; ROS, reactive oxygen species; MFI, mean fluorescence intensity.

also determined that the level of JNK was notably upregulated following CTPG-W treatment (Fig. 5C). The results indicated that CTPG-W may induce the apoptosis of Eca-109 cells through a mitochondrial-dependent pathway.

The effect of CTPG-W on intracellular ROS generation. ROS could reduce $\Delta \psi \mathrm{m}$ to induce apoptosis (36). To investigate whether CTPG-W can increase ROS production, Eca-109 cells were treated with different concentrations of CTPG-W. Cells were collected at the indicated time points and stained with DCFH-DA. The production of intracellular ROS in Eca-109 cells was determined by flow cytometry. As depicted in Fig. 6A, $800 \mu \mathrm{g} / \mathrm{ml}$ CTPG-W significantly increased ROS production from 2-6 h, and decreased from 12-24 h. Additionally, $400 \mu \mathrm{g} / \mathrm{ml}$ CTPG-W significantly increased ROS production from 12-24 h. Furthermore, $200 \mu \mathrm{g} / \mathrm{ml}$ CTPG-W did not notably alter ROS production. The dynamic changes of ROS production may be associated with Eca-109 cell apoptosis. It was also determined that CTPG-W had free radical scavenging activity (Fig. 6B), which may be associated with the decreased ROS production in Eca-109 cells treated with $800 \mu \mathrm{g} / \mathrm{ml}$ CTPG-W after $12 \mathrm{~h}$.

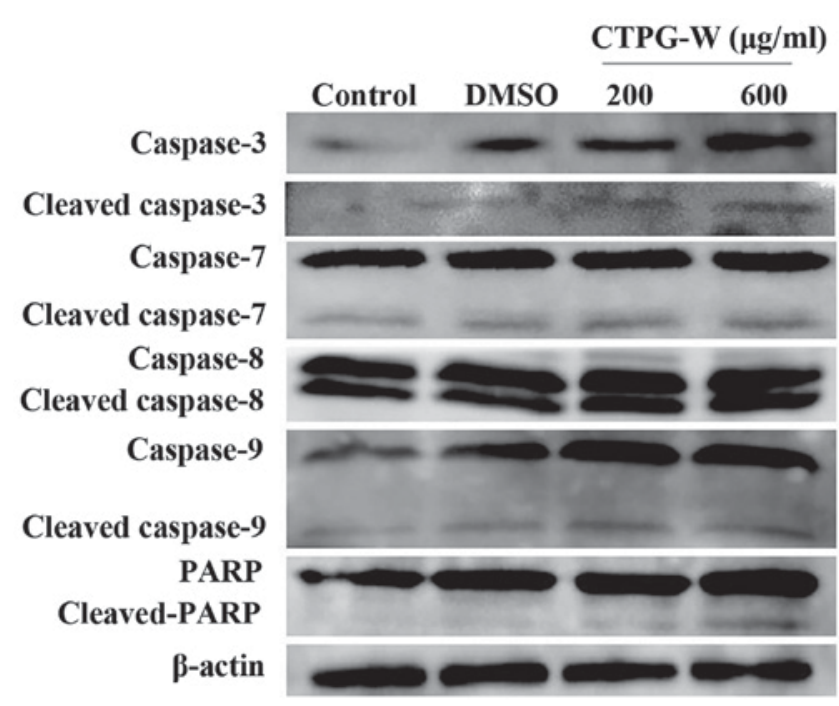

Figure 7. The levels of cleaved-caspases and cleaved-PARP following CTPG-W treatment. Proteins were isolated from Eca-109 cells treated with CTPG-W for $24 \mathrm{~h}$ and the levels of cleaved-caspases and cleaved-PARP were detected with western blot analysis. DMSO, dimethyl sulfoxide; CTPG-W, water-soluble phenylethanoid glycosides of $C$. tubulosa; PARP, poly (ADP-ribose) polymerase. 
CTPG-W upregulates the activity of caspase-3, caspase-7, caspase-9 and PARP. The release of cytochrome $c$ due to $\Delta \psi \mathrm{m}$ reduction could activate the caspase proteases to induce apoptosis (29,30,37). Following CTPG-W treatment for $24 \mathrm{~h}$, the activation of caspase-3, 7, 8, 9 and PARP was detected by western blot analysis. Compared with the control, the levels of cleaved-caspase-9, cleaved-caspase-7, cleaved-caspase-3 and cleaved-PARP, but not the levels of cleaved-caspase-8, were upregulated by CTPG treatment in a dose-dependent manner (Fig. 7). These results indicated that CTPG-W reduced $\Delta \psi \mathrm{m}$ and promoted cytochrome $c$ release to activate caspases that induce the apoptosis of Eca-109 cells.

\section{Discussion}

Traditional CHM could induce apoptosis of esophageal cancer cells through different pathways, including the extrinsic death receptor, intrinsic mitochondrial and endoplasmic reticulum stress pathways (29). Our previous study demonstrated that CTPG, as the major component of C. tubulosa, inhibited the growth of melanoma B16-F10 cells through the induction of apoptosis via a mitochondrial-dependent pathway (24). In the present study, the antitumor effect of CTPG-W on Eca-109 cells was investigated and it was determined that CTPG-W suppressed the growth of Eca-109 cells, induced apoptosis and cell cycle arrest, reduced $\Delta \psi \mathrm{m}$, increased the release of cytochrome $c$ and activated caspases. CTPG and CTPG-W could induce the apoptosis and cell cycle arrest in cancer cells. However, the accurate mechanisms are different due to the different components of CTPG (26.64\% echinacoside, $10.19 \%$ acteoside and $1.71 \%$ isoacteoside) and CTPG-W (39.16\% echinacoside and $2.44 \%$ acteoside). CTPG arrested B16-F10 cells at the $\mathrm{G}_{0} / \mathrm{G}_{1}$ phases, but CTPG-W arrested Eca- 109 cells at the $S$ phase (24). ROS production was dose-dependently increased by CTPG, but it indicated a change in a time-dependent manner by high dose of CTPG-W, which increased significantly at the beginning of CTPG-W treatment (2-6 h) and decreased significantly after $12 \mathrm{~h}$, compared with the control. A possible reason is that the major component of CTPG-W is echinacoside. A number of studies reported that echinacoside could inhibit ROS production and ROS-induced apoptosis to exert its neuroprotective and anti-aging effects (38-40). Similarly, the free radical scavenging activity was observed in the present study. Therefore, it was speculated that some components, including verbascoside, iso-verbascoside and salidroside in a high dose of CTPG-W might immediately induce ROS generation to cause apoptosis of Eca-109 cells $(41,42)$, and then ROS was scavenged by echinacoside. Another possible reason for the differences in ROS production by CTPG and CTPG-W is that different cell lines were used in this study and previous study (24). Dong et al (43) reported that echinacoside could induce the apoptosis of human SW480 colorectal cancer cells through the generation of oxidative DNA damages without increased ROS levels.

CTPG-W treatment reduced $\Delta \psi \mathrm{m}$ and caused the release of cytochrome $c$, which promotes the cleavage of caspase-9 (28). Consistently, the levels of cleaved-caspase- 9 were upregulated by CTPG-W treatment. Subsequently, the active caspase- 9 can activate caspase-3 to induce apoptosis (44). The levels of cleaved-caspase-3 were also upregulated by CTPG-W treatment. However, caspase- 8 was not activated by CTPG-W, indicating that the extrinsic death receptor pathway was not involved in the apoptosis induced by CTPG-W. These observations indicate that CTPG-W induces apoptosis of Eca-109 cells through the activation of a mitochondrial-dependent pathway.

PARP serves important roles in the genomic stability and can be cleaved by the active caspases, particularly caspase- 3 and -7 (45). It was determined that CTPG-W treatment activated caspase-3 and -7 , which may cleave PARP to inhibit DNA repair and cause apoptosis.

CTPG-W also dose- and time-dependently suppresses the growth of human hepatocellular carcinoma BEL-7404 cells (unpublished data). Although CTPG-W inhibits the growth of Eca-109 and BEL-7404 cells, it promotes the proliferation of splenocytes, which may be due to the content of polysaccharides $(\sim 50 \%)$ in CTPG-W (46). Similarly, a number of studies have reported that polysaccharides can promote the proliferation of splenocytes (46-49). In the mouse model, it was determined that CTPG-W significantly increased the spleen index, compared with the control group, but did not affect the body weight and the other organ indexes including heart, liver, kidney and lung (unpublished data), indicating that CTPG-W has no cytotoxic effect on normal cells.

Collectively, the data indicated that CTPG-W inhibits the growth of Eca-109 cells by induction of apoptosis via a mitochondrial-dependent pathway.

\section{Acknowledgements}

The authors would like to thank Dr Jianhua Yang (Baylor College of Medicine) for polishing the manuscript.

\section{Funding}

This study was supported by the 13th Five-Year Plan for Key Discipline Biology Bidding Project (grant no. 17SDKD0202), Xinjiang Normal University and Key Laboratory of Special Environment Biodiversity Application and Regulation in Xinjiang (grant no. XJTSWZ-2017-04) to JL and the Chinese National Natural Science Foundation Grant (grant no. 31760260$)$ to XW.

\section{Availability of data and materials}

Data and materials used and analyzed during the present study are available from the corresponding author on reasonable request.

\section{Authors' contributions}

CF, AA, YY and QC performed the experiments. LX, JLv and $\mathrm{XW}$ analyzed the data and the prepared figures. JinyuL and JinyaoL designed the project and wrote the manuscript.

\section{Ethics approval and consent to participate}

All animal experiments were approved by the Committee on the Ethics of Animal Experiments of Xinjiang Key Laboratory of Biological Resources and Genetic Engineering (approval, no. BRGE-AE001; Xinjiang University). 


\section{Patient consent for publication}

Not applicable.

\section{Competing interests}

The authors declare that they have no competing interest.

\section{References}

1. Global Burden of Disease Cancer Collaboration, Fitzmaurice C, Allen C, Barber RM, Barregard L, Bhutta ZA, Brenner H, Dicker DJ, Chimed-Orchir O, Dandona R, Dandona L, et al: Global, regional, and national cancer incidence, mortality, years of life lost, years lived with disability, and disability-adjusted life-years for 32 cancer groups, 1990 to 2015: A systematic analysis for the global burden of disease study. JAMA Oncol 3 : 524-548, 2017.

2. Torre LA, Bray F, Siegel RL, Ferlay J, Lortet-Tieulent J and Jemal A: Global cancer statistics, 2012. CA Cancer J Clin 65: 87-108, 2015

3. Chen W, Zheng R, Baade PD, Zhang S, Zeng H, Bray F, Jemal A, $\mathrm{Yu}$ XQ and He J: Cancer statistics in China, 2015. CA Cancer J Clin 66: 115-132, 2016.

4. Smyth EC, Lagergren J, Fitzgerald RC, Lordick F, Shah MA, Lagergren P and Cunningham D: Oesophageal cancer. Nat Rev Dis Primers 3: 17048, 2017.

5. Samson P and Lockhart AC: Biologic therapy in esophageal and gastric malignancies: Current therapies and future directions. J Gastrointest Oncol 8: 418-429, 2017.

6. Zhang XW, Liu W, Jiang HL and Mao B: Chinese herbal medicine for advanced non-small-cell lung cancer: A systematic review and meta-analysis. Am J Chin Med 46: 923-952, 2018.

7. Zhu H, Hao J, Niu Y, Liu D, Chen D and Wu X: Molecular targets of Chinese herbs: A clinical study of metastatic colorectal cancer based on network pharmacology. Sci Rep 8: 7238,2018

8. Sun L, Fahey P, Zhu X, Ng W, Chen ZP, Qiu Y, Lai H, Lin J and Lin L: A cohort study to examine the use of chinese herbal medicine in combination with conventional therapies for patients with hepatocellular carcinoma in China. Integr Cancer Ther 17: 902-911, 2018.

9. Chung VC, Wu X, Hui EP, Ziea ET, Ng BF, Ho RS, Tsoi KK, Wong SY and Wu JC: Effectiveness of chinese herbal medicine for cancer palliative care: Overview of systematic reviews with meta-analyses. Sci Rep 5: 18111, 2015.

10. Chen X, Deng L, Jiang X and Wu T: Chinese herbal medicine for oesophageal cancer. Cochrane Database Syst Rev 22: CD004520, 2016.

11. Cai YM, Zhu H, Niu JX, Bing L, Sun Z, Zhang WH, Ying JZ, Yin XD, Li J, Pang Y and Li JL: Identification of herb pairs in esophageal cancer. Complement Med Res 24: 40-45, 2017.

12. Yue GG, Lee JK, Li L, Chan KM, Wong EC, Chan JY, Fung KP, Lui VW, Chiu PW and Lau CB: Andrographis paniculata elicits anti-invasion activities by suppressing TM4SF3 gene expression and by anoikis-sensitization in esophageal cancer cells. Am J Cancer Res 5: 3570-3587, 2015.

13. Li L, Yue GG, Lee JK, Wong EC, Fung KP, Yu J, Lau CB and Chiu PW: The adjuvant value of Andrographis paniculata in metastatic esophageal cancer treatment-from preclinical perspectives. Sci Rep 7: 854, 2017.

14. Nagata T, Toume K, Long LX, Hirano K, Watanabe T, Sekine S, Okumura T, Komatsu K and Tsukada K: Anticancer effect of a kampo preparation daikenchuto. J Nat Med 70: 627-633, 2016.

15. Fan C, Yang Y, Liu Y, Jiang S, Di S, Hu W, Ma Z, Li T, Zhu Y, Xin $\mathrm{Z}$, et al: Icariin displays anticancer activity against human esophageal cancer cells via regulating endoplasmic reticulum stress-mediated apoptotic signaling. Sci Rep 6: 21145, 2016.

16. Liu W, Li SY, Huang XE, Cui JJ, Zhao T and Zhang H: Inhibition of tumor growth in vitro by a combination of extracts from Rosa roxburghii tratt and Fagopyrum cymosum. Asian Pac J Cancer Prev 13: 2409-2414, 2012.

17. Ma YC, Ke Y, Zi X, Zhao W, Shi XJ and Liu HM: Jaridonin, a novel ent-kaurene diterpenoid from Isodon rubescens, inducing apoptosis via production of reactive oxygen species in esophageal cancer cells. Curr Cancer Drug Targets 13: 611-624, 2013.
18. Fan W, Sun L, Zhou JQ, Zhang C, Qin S, Tang Y, Liu Y, Lin SS and Yuan ST: Marsdenia tenacissima extract induces G0/G1 cell cycle arrest in human esophageal carcinoma cells by inhibiting mitogen-activated protein kinase (MAPK) signaling pathway. Chin J Nat Med 13: 428-437, 2015.

19. Peng KZ, Ke Y, Zhao Q, Tian F, Liu HM, Hou G and Lu Z: OP16, a novel ent-kaurene diterpenoid, potentiates the antitumor effect of rapamycin by inhibiting rapamycin-induced feedback activation of Akt signaling in esophageal squamous cell carcinoma. Biochem Pharmacol 140: 16-27, 2017.

20. Shi H, Shi D, Wu Y, Shen Q and Li J: Qigesan inhibits migration and invasion of esophageal cancer cells via inducing connexin expression and enhancing gap junction function. Cancer Lett 380: 184-190, 2016.

21. Jia YS, Hu XQ, Li JA, Andras S, Hegyi G and Han BS: Tonglian Decoction arrests the cell cycle in $\mathrm{S}$-phase by targeting the nuclear factor-kappa B signal pathway in esophageal carcinoma Eca109 cells. Chin J Integr Med 22: 384-389, 2016.

22. Lin LW, Hsieh MT, Tsai FH, Wang WH and Wu CR: Anti-nociceptive and anti-inflammatory activity caused by Cistanche deserticola in rodents. J Ethnopharmacol 83: 177-182, 2002.

23. Wu CR, Lin HC and Su MH: Reversal by aqueous extracts of Cistanche tubulosa from behavioral deficits in Alzheimer's disease-like rat model: Relevance for amyloid deposition and central neurotransmitter function. BMC Complement Altern Med 14: 202, 2014

24. Li J, Aipire A, Gao L, Huo S, Luo J and Zhang F: Phenylethanoid glycosides from Cistanche tubulosa inhibits the growth of B16-F10 cells both in vitro and in vivo by induction of apoptosis via mitochondria-dependent Pathway. J Cancer 7: 1877-1887, 2016.

25. Brand-Williams W, Culivier ME and Berset C: Use of a free radical method to evaluate antioxidant activity. LWT-Food Sci Technol 28: 25-30, 1995.

26. Bansal P, Paul P, Nayak PG, Pannakal ST, Zou JH, Laatsch H, Priyadarsini KI and Unnikrishnan MK: Phenolic compounds isolated from Pilea microphylla prevent radiation-induced cellular DNA damage. Acta Pharm Sin B 1: 226-235, 2011.

27. Wang R, Zhang Q, Peng X, Zhou C, Zhong Y, Chen X, Qiu Y, Jin M, Gong M and Kong D: Stellettin B Induces G1 arrest, apoptosis and autophagy in human non-small cell lung cancer A549 cells via blocking PI3K/Akt/mTOR pathway. Sci Rep 6: 27071, 2016.

28. Sinha K, Das J, Pal PB and Sil PC: Oxidative stress: The mitochondria-dependent and mitochondria-independent pathways of apoptosis. Arch Toxicol 87: 1157-1180, 2013.

29. Zhang YS, Shen Q and Li J: Traditional chinese medicine targeting apoptotic mechanisms for esophageal cancer therapy. Acta Pharmacol Sin 37: 295-302, 2016.

30. Tait SW and Green DR: Mitochondria and cell death: Outer membrane permeabilization and beyond. Nat Rev Mol Cell Boil 11: 621-632, 2010.

31. Galluzzi L, Kepp O and Kroemer G: Mitochondria: Master regulators of danger signalling. Nat Rev Mol Cell Boil 13: 780-788, 2012.

32. Chong ZZ, Lin SH, Li F and Maiese K: The sirtuin inhibitor nicotinamide enhances neuronal cell survival during acute anoxic injury through AKT, BAD, PARP, and mitochondrial associated 'anti-apoptotic' pathways. Curr Neurovasc Res 2: 271-285, 2005.

33. Zeng GZ, Wang Z, Zhao LM, Fan JT and Tan NH: NF-kB and JNK mediated apoptosis and G0/G1 arrest of HeLa cells induced by rubiarbonol $\mathrm{G}$, an arborinane-type triterpenoid from rubia yunnanensis. J Ethnopharmacol 220: 220-227, 2018.

34. Lei $\mathrm{K}$ and Davis RJ: JNK phosphorylation of Bim-related members of the Bcl2 family induces bax-dependent apoptosis. Proc Natl Acad Sci USA 100: 2432-2437, 2003.

35. Tournier C, Hess P, Yang DD, Xu J, Turner TK, Nimnual A, Bar-Sagi D, Jones SN, Flavell RA and Davis RJ: Requirement of JNK for stress-induced activation of the cytochrome c-mediated death pathway. Science 288: 870-874, 2000.

36. Ling YH, Liebes L, Zou Y and Perez-Soler R: Reactive oxygen species generation and mitochondrial dysfunction in the apoptotic response to bortezomib, a novel proteasome inhibitor, in human H460 non-small cell lung cancer cells. J Biol Chem 278: 33714-33723, 2003.

37. Hotchkiss RS and Nicholson DW: Apoptosis and caspases regulate death and inflammation in sepsis. Nat Rev Immunol 6: 813-822, 2006 
38. Kuang R, Sun Y, Yuan W, Lei L and Zheng X: Protective effects of echinacoside, one of the phenylethanoid glycosides, on $\mathrm{H}(2) \mathrm{O}(2)$-induced cytotoxicity in $\mathrm{PC} 12$ cells. Planta Med 75: 1499-1504, 2009.

39. Zhao Q, Yang X, Cai D, Ye L, Hou Y, Zhang L, Cheng J, Shen Y, Wang K and Bai Y: Echinacoside protects against MPP(+)-induced neuronal apoptosis via ROS/ATF3/CHOP pathway regulation. Neurosci Bull 32: 349-362, 2016

40. Wang YH, Xuan ZH, Tian S and Du GH: Echinacoside protects against 6-hydroxydopamine-induced mitochondrial dysfunction and inflammatory responses in $\mathrm{PC} 12$ cells via reducing ROS production. Evid Based Complement Alternat Med 2015: 189239, 2015.

41. Lecci RM, Logrieco A and Leone A: Pro-oxidative action of polyphenols as action mechanism for their pro-apoptotic activity. Anticancer Agents Med Chem 14: 1363-1375, 2014.

42. Zeng W, Xiao T, Cai A, Cai W, Liu H, Liu J, Li J, Tan M, Xie L, Liu Y, et al: Inhibiting ROS-TFEB-dependent autophagy enhances salidroside-induced apoptosis in human chondrosarcoma cells. Cell Physiol Biochem 43: 1487-1502, 2017.

43. Dong L, Yu D, Wu N, Wang H, Niu J, Wang Y and Zou Z: Echinacoside induces apoptosis in human SW480 colorectal cancer cells by induction of oxidative DNA damages. Int J Mol Sci 16: 14655-14668, 2015.

44. Sun SY: Apoptosis induction by chemopreventive agents. Drug News perspect 14: 75-80,2001.
45. Herceg Z and Wang ZQ: Functions of poly(ADP-ribose) polymerase (PARP) in DNA repair, genomic integrity and cell death. Mutat Res 477: 97-110, 2001.

46. Jiang L, Yu Z, Lin Y, Cui L, Yao S, Lv L and Liu J: Low-molecular-weight polysaccharides from agaricus blazei murrill modulate the Th1 response in cancer immunity. Oncol Lett 15: 3429-3436, 2018.

47. Yang SF, Zhuang TF, Si YM, Qi KY and Zhao J: Coriolus versicolor mushroom polysaccharides exert immunoregulatory effects on mouse B cells via membrane Ig and TLR-4 to activate the MAPK and NF- $\kappa$ B signaling pathways. Mol Immunol 64: 144-151, 2015.

48. Son YO, Kook SH and Lee JC: Glycoproteins and polysaccharides are the main class of active constituents required for lymphocyte stimulation and antigen-specific immune response induction by traditional medicinal herbal plants. J Med Food 20: 1011-1021, 2017.

49. Swanson-Mungerson M, Incrocci R, Subramaniam V, Williams P, Hall ML and Mayer AMS: Effects of cyanobacteria oscillatoria sp. lipopolysaccharide on B cell activation and Toll-like receptor 4 signaling. Toxicol Lett 275: 101-107, 2017.

This work is licensed under a Creative Commons Attribution-NonCommercial-NoDerivatives 4.0 International (CC BY-NC-ND 4.0) License. 